\title{
Dysfunction of Synaptic Vesicle Endocytosis in Parkinson's Disease
}

\author{
Li Zou, Ye Tian and Zhentao Zhang* \\ Department of Neurology, Renmin Hospital of Wuhan University, Wuhan, China
}

Parkinson's disease (PD) is the second most common neurodegenerative disorder after Alzheimer's disease. It is a chronic and progressive disorder estimated to affect at least 4 million people worldwide. Although the etiology of PD remains unclear, it has been found that the dysfunction of synaptic vesicle endocytosis (SVE) in neural terminal happens before the loss of dopaminergic neurons. Recently, accumulating evidence reveals that the PD-linked synaptic genes, including DNAJC6, SYNJ1, and SH3GL2, significantly contribute to the disruptions of SVE, which is vital for the pathogenesis of PD. In addition, the proteins encoded by other PD-associated genes such as SNCA, LRRK2, PRKN, and $D J-1$ also play key roles in the regulation of SVE. Here we present the facts about SVE-related genes and discussed their potential relevance to the pathogenesis of PD.

Keywords: Parkinson's disease, synaptic dysfunction, neurodegeneration, $\alpha$-synuclein, SYNJ1

\section{INTRODUCTION}

Parkinson's disease (PD) is the second most common neurodegenerative disease after Alzheimer's disease (AD) (De Lau and Breteler, 2006). The prevalence of PD in those older than 65 is about $1.7 \%$. PD is usually diagnosed based on motor symptoms (e.g., rest tremor, bradykinesia, rigidity, etc.). The pathological characteristics of PD are the degeneration and loss of dopaminergic neurons in the nigrostriatal pathway. However, the pathogenesis of PD remains unclear. Studies have confirmed that in PD, neuronal axon degeneration and/or synaptic dysfunction prior to the loss of dopamine neurons (Burke and O'malley, 2013; Kurowska et al., 2016). Most synaptic functions are effective by the release and reuptake of neurotransmitters stored in the synaptic vesicles. The recycling of synaptic vesicles plays a decisive role in the function of the synapse. Increasing evidence suggests that dysfunction of synapse may play an important role in the onset and progression of PD. Synaptic dysfunction happens in the early stage of PD and may be one of the causes to trigger the loss of dopaminergic neurons (Schirinzi et al., 2016). Several genes that regulate synaptic function are found to be involved in the pathological process of PD, highlighting the importance of further studies on synaptic dysfunction in PD. Therefore, we briefly discuss the experimental and genetic evidence on synaptic dysfunction in $\mathrm{PD}$, in order to provide a prospective view on the treatment of PD.

eceived: 19 October 2020 Accepted: 28 April 2021

Published: 20 May 2021

\section{SYNAPTIC VESICLE RECYCLING}

Presynaptic terminals are highly differentiated structures in which synaptic vesicles (SVs) accumulate near the electron-dense active region and are physically and biochemically prepared for fusion and recycling under the action of a highly conserved group of molecules (Rizzoli and Betz, 2005; Hua et al., 2011; Imig et al., 2014). The activity of presynaptic vesicles can 
be approximately divided into the following main steps (Südhof, 2004; Watanabe et al., 2014; Watanabe and Boucrot, 2017): (1) Neurotransmitters are pumped into the vesicles through the neurotransmitter transporter on the surface of the vesicles; (2) The vesicles are transported to the near-activated area of the presynaptic neuron end, where they are accumulated relatively; (3) The vesicles to be released are spatially close to or directly anchored to the active zone of presynaptic plasma membrane; (4) The action potential is transmitted to the axis at the terminal end, the voltage-dependent calcium channel opening of the presynaptic membrane causes calcium influx; (5) High concentration of calcium ions fuse the vesicle with the presynaptic membrane and forms an opening, and the neurotransmitter is released through the opening. (6) Endocytosis of vesicles after fusion with the presynaptic membrane is thought to have two pathways: faster clathrinindependent endocytic processes, like ultrafast endocytosis, and slower clathrin-mediated endocytosis; (7) Neurotransmitters are re-introduced into the vesicles after endocytosis by the neurotransmitter transporter (see Figure 1).

There are also other modes for synaptic vesicle retrieval, including kiss-and-run and several variations of bulk endocytosis such as ultrafast and activity-dependent bulk endocytosis (Saheki and De Camilli, 2012; Soykan et al., 2016; Cousin, 2017; Milosevic, 2018; Chanaday et al., 2019). Recently, more studies consider that bulk retrieval pathways are also important rather than as an addition (Soykan et al., 2016; Chanaday et al., 2019). These modes of endocytosis have also been found to be regulated by proteins like dynamin, endophilin A1, and synaptojanin 1 (Wu Y. et al., 2014; Soykan et al., 2016; Watanabe et al., 2018; Chanaday et al., 2019). However, the precise time scale of the modes of SV recycling is highly debated ( $\mathrm{He}$ and $\mathrm{Wu}, 2007$; Soykan et al., 2017; Watanabe and Boucrot, 2017). It is generally accepted that an adaptor protein (such as adaptor protein 2, AP2 ) is required for SV cargo detection and clathrin recruitment to initiate the most classic form of endocytosis. Meanwhile, clathrin-mediated endocytosis is considered the main mode of SV recycling (Soykan et al., 2016; Chanaday et al., 2019). From this point of view, the origin of synaptic vesicles from the cell membrane is SVE, in preparation for neurotransmission (Saheki and De Camilli, 2012). We will first outline the steps involved in this SVE process.

Many molecules and their families, such as endophilin, dynamin, synaptojanin1, and auxilin, including mutual interaction, are involved in the endocytic process to mediate membrane deformation, fission and clathrin uncoating. Generally, the clathrin-dependent endocytosis process can be divided into four steps (Mcmahon and Boucrot, 2011; Ramanan et al., 2011): (1) nucleation of clathrin-coated pits; (2) cargo capture; (3) curvature induction and membrane invagination or coat growth; (4) vesicle scission and clathrin uncoating. SVE begins by recruiting adaptor proteins to the cytoplasmic surface of the plasma membrane to the PtdsIns $(4,5) \mathrm{P}_{2}$ lipidenriched region (Kelly et al., 2014). These adaptor proteins (such as AP-2, AP180, and epsin) regulate cargo sorting to ensure proper protein internalization with vesicles. Next, the membrane benders such as BAR domain proteins are recruited to the plasma membrane, where they mediate the invagination of vesicles (Frost et al., 2009; Trempe et al., 2009; Ramanan et al., 2011; Galic et al., 2012; Pechstein et al., 2015). The vesicles are generated from the plasma membrane, which is rich in PtdsIns $(4,5) \mathrm{P}_{2}$, and contains various inositolphosphates, which mediates the recycling of vesicles (Rohrbough and Broadie, 2005). Endophilin A1 could subsequently interact with dynamin and recruits synaptojanin 1 to the membrane interface (Schuske et al., 2003; Verstreken et al., 2003; Watanabe et al., 2018). Dynamin then constricts the neck and mediates clathrin-coated vesicles (CCVs) fission from the plasma membrane, through its GTPase activity (Marks et al., 2001; Daumke et al., 2014). When the CCVs are free, synaptojanin 1 exerts $5^{\prime}$-phosphatase activity to dephosphorylate PtdsIns $(4,5) \mathrm{P}_{2}$ to PtdsIns4P, which can be further dephosphorylated to PtdsIns (Chang-Ileto et al., 2011; Saheki and De Camilli, 2012). Dephosphorylation of PtdsIns $(4,5) \mathrm{P}_{2}$ causes the release of AP-2, which relies on PtdsIns $(4,5) \mathrm{P}_{2}$ for its vesicle binding, and allow auxilin to bind the CCVs through its PTEN-like and clathrin-binding domains (Yim et al., 2010; Saheki and De Camilli, 2012). Auxilin is a cofactor for HSC70, which simulates the removal of the clathrin coat through its ATPase activity (Morgan et al., 2001; Eisenberg and Greene, 2007; Yim et al., 2010; Saheki and De Camilli, 2012). Once the clathrin coat is fully removed, dopamine or other neurotransmitters can be packaged into the nascent vesicle, and quickly transported to synaptic vesicle pools in anticipation of the next neuronal stimulation (Ramanan et al., 2011; Saheki and De Camilli, 2012).

The SVE-dependent regeneration of synaptic vesicles is a highly regulated process and essential to restore neurotransmission. SVE is a unique system that is regulated by the phosphorylation-dephosphorylation-phosphorylation events of protein and lipids (Cousin and Robinson, 2001). These proteins include dynamin, synaptojanin1, amphiphysin 1 and 2, and epsin (Cousin and Robinson, 2001). Under the quiescent condition, SVE proteins are constitutively phosphorylated, thereby inhibiting their association to other proteins in the endocytic pathway (Cousin and Robinson, 2001). When neurons are stimulated, $\mathrm{Ca}^{2+}$ flows into the cell and activates $\mathrm{Ca}^{2+}$ dependent calcineurin activity, which rapidly dephosphorylates endocytic proteins, allowing them to interact and recruit to endocytic sites (Cousin and Robinson, 2001; Wu X.S. et al., 2014; Cottrell et al., 2016). SVE protein inactivation through rephosphorylation occurs on a much slower timescale in a stepwise process. This process has been shown to be mediated in part by Cdk5 and Minibrain kinase (Tan et al., 2003; Chen et al., 2014). However, other kinases may also participate in the proper time/space control of SVE in neural terminals (Pelkmans et al., 2005).

\section{AXON DEGENERATION AND SVE DYSFUNCTION IN PD}

Emerging evidences from human post-mortem studies, functional neuroimaging, genetic studies and neurotoxin models show that axon degeneration and SVE dysfunction may 


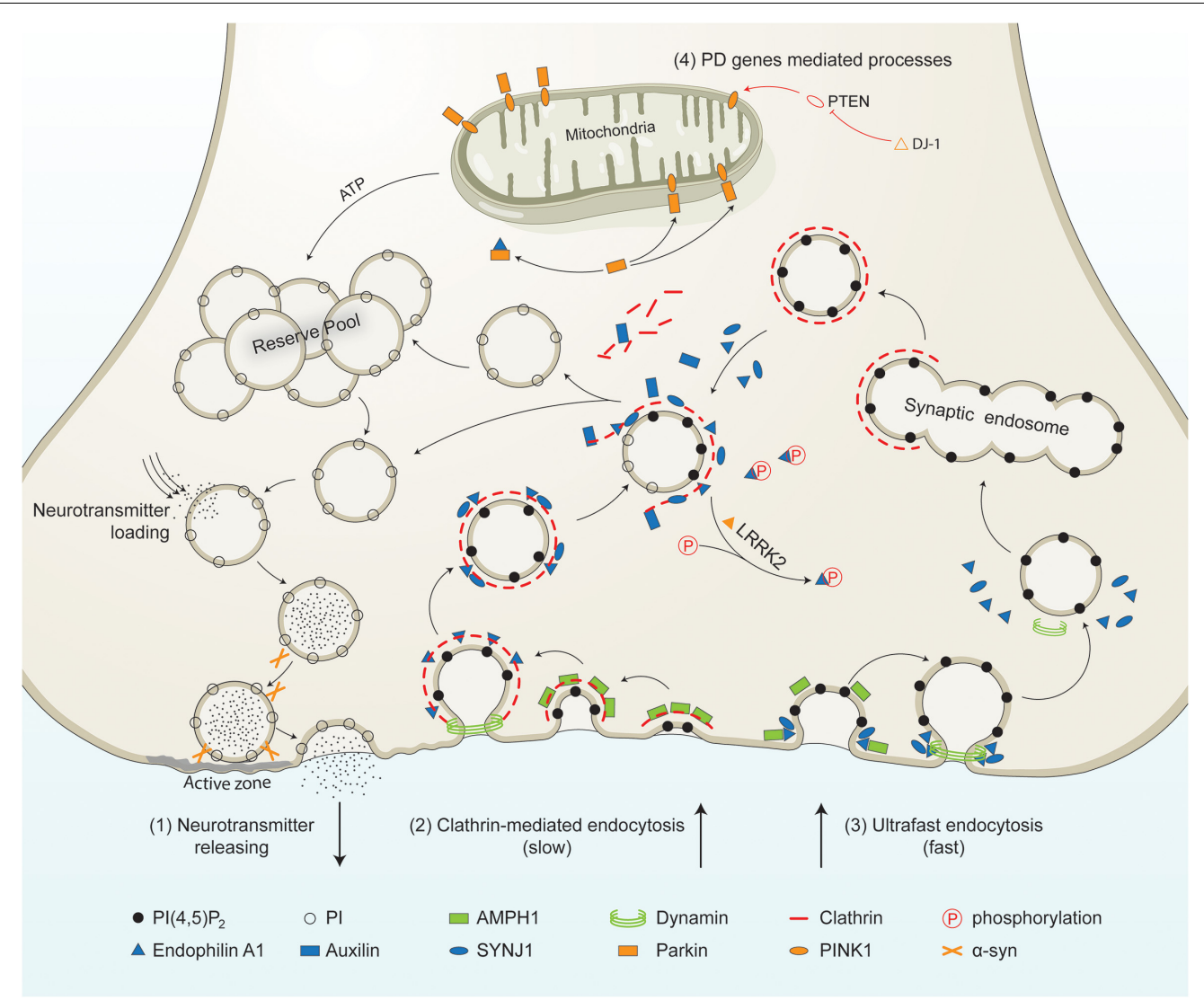

FIGURE 1 | PD-linked and SVE-associated genes in synaptic vesicle recycling. Schematic representation of a presynaptic terminal showing the roles of PD-linked genes (orange) and SVE-associated genes (blue) in synaptic vesicle recycling. It shows the neurotransmitter release process, clathrin-mediated endocytosis, ultrafast endocytosis, and other processes in which PD genes are involved. (1) Neurotransmitter releasing. Synaptic vesicles from the reserve pool or derived from the uncoating process are loaded with neurotransmitters. The vesicles move toward the active zone and then fuse to the plasma membrane in the presence of synaptic proteins including $\alpha$-syn. Neurotransmitters are released into the synaptic cleft. (2) Clathrin-mediated endocytosis. This process is initiated by the coating of the plasma membrane by clathrin. The coated membrane is curved via the activity of AMPH1. Then endophilin mediates the invagination of the clathrin-coated plasma membrane. Endophilin A1 recruits dynamin to the neck of the clathrin-coated vesicles (CCVs). Endophilin A1 contains several SH3 domains and interacts with SYNJ1 and/or Parkin. Once recruited, SYNJ1 dephosphorylates $\mathrm{PI}(4,5 \mathrm{P})_{2}$ into PI, shedding clathrin and its adaptor from the bilayer. LRRK2 phosphorylates endophilin, leading to dissociation of the later from CCVs. The removal of the clathrin coat is mediated by auxilin. Finally, the uncoated endocytic vesicles move into the reserve pool, or directly undergo loading and releasing process. (3) Ultrafast endocytosis. During this type of endocytosis, AMPH1 and endophilin A1 are recruited to the plasma membrane, and regulate the curvature of the emerging vesicle. Dynamin then constricts the neck and mediates synaptic vesicle fission from the plasma membrane. The large endocytic vesicles cluster and fuse to form synaptic endosomes. The synaptic endosomes are further coated by clathrin to generate CCVs, which undergo clathrin-uncoating and generate endocytic vesicles. (4) Other processes mediated by PD-related genes. PTEN is a lipid phosphatase that is inhibited by DJ-1. PTEN increases the level of PINK1 in the mitochondrial. PINK1 is released by the mitochondria and triggers neuronal differentiation. The PTEN-Parkin axis is necessary for proper mitochondrial function. This guarantees ATP synthesis and is necessary for most processes, such as vesicle fusion and the mobilization of the vesicles in the reserve pool during synaptic vesicle recycling.PI $(4,5) \mathrm{P}_{2}$, phosphatidylinositol 4,5-bisphosphate; PI, phosphatidylinositol; $\alpha$-syn, alpha-synuclein; AMPH1, amphiphysin 1; SYNJ1, synaptojanin 1; LRRK2, leucine-rich repeat serine/threonine protein kinase 2; PTEN, phosphatase and tensin homolog; PINK1, PTEN induced putative kinase 1; DJ-1, Parkinson's disease protein 7; ATP, adenosine triphosphate.

be the earliest feature of the disease (Lee et al., 2000; Serra et al., 2002; Dauer and Przedborski, 2003; Shin et al., 2008; Li L.H. et al., 2009; Qing et al., 2009; Cheng et al., 2010; Kagi et al., 2010; Schulz-Schaeffer, 2010; Peelaerts et al., 2015). Furthermore, the molecular mechanisms of degeneration of axons are distinct from those of neuron soma (Burke and O'malley, 2013). SVE dysfunction is one of presynaptic terminal degeneration mechanisms. But as SVE is not unique to dopaminergic neurons in the ventral midbrain, the specific vulnerability of these neurons to SVE deficiency in PD remains unclear. PD-linked SYNJ1 R258Q mouse models revealed delays in SVE and marked changes in dopaminergic axon terminals in the dorsal striatum, highlighting a region-specific vulnerability of these neurons to synaptojanin 1 dysfunction (see later) (Cao et al., 2017). In LRRK2 G2019S transgenic mice, SVE dysfunction including accumulation of CCVs and decreased synaptic densities were found specifically in dopaminergic pathway, resulting in axon degeneration and selective impairment of dopaminergic neurons (Pan et al., 2017). One possibility might be the sensitivity of dopaminergic neurons to the accumulation of cytosolic dopamine. Cytosolic dopamine is an oxidative stressor, suggesting that dopamine itself is a factor of particular 
vulnerability to numerous synaptic components (Chen et al., 2008). Hence, disruption of SVE in PD models may interrupt normal dopamine homeostasis by lowering dopamine loading into cycling SVs, resulting in increased cytosolic dopamine that is toxic. In a rat model, acute overexpression of human $\alpha$-synuclein led to the specific degeneration of striatal terminals without nigral cell death (Busch et al., 2014; Eguchi et al., 2017; Medeiros et al., 2017). Moreover, dopamine is packaged into synaptic vesicles regenerated from SVE using a proton gradient created by vATPases located on the membrane surface of synaptic vesicles (Eiden et al., 2004). vATPase activity is dramatically inhibited by the clathrin coat and immediately restored once the coat was removed by auxilin (Farsi et al., 2018). Therefore, CCVs can be uncoated by means of a series of synaptic proteins including synaptojanin 1 and auxilin, and turned into SVs (Morgan et al., 2002). These newborn SVs will be loaded with other neurotransmitters such as dopamine, stored in the release vesicles pool, and/or fused with the plasma membrane to complete exocytosis (Morgan et al., 2002). The above evidence indicates that the dysfunction of SVE may cause dopamine to be incorrectly packed into vesicles, leading to increased cytosolic dopamine, ultimately contributing to dopaminergic neurodegeneration beginning at the axon terminals.

\section{PD GENES INVOLVED IN SVE AT THE NERVE TERMINAL}

Parkinson's disease is considered as a multifactorial disease caused by both genetic and environmental factors. Most of the PD patients are sporadic, but about 5\% of them are caused by genetic mutations. More than 20 genes have been found to cause PD. Interestingly, some PD-associated genes, including $S N C A$, LRRK2, and PRKN, may also be potential regulators of SVE.

\section{$\alpha$-Synuclein in SVE}

$\alpha$-Synuclein, encoded by the SNCA gene, is the major protein component of the Lewy bodies in the brain of PD patients. It is a small protein $(14 \mathrm{kDa})$ consisting of three functional domains: a highly conserved $\mathrm{N}$-terminal domain that can form an amphiphilic $\alpha$-helix for lipid interactions, a central hydrophobic NAC structure domain, which is involved in the formation of $\beta$-sheet-rich amyloid fibrils, and the unfolded C-terminal tail, which is known to bind VAMP2/synaptic short fibers 2 (Davidson et al., 1998; Giasson et al., 2001). All PD-related mutations of SNCA, A30P, E46K, H50Q, G51D, and A53T are located in the amphiphilic region, suggesting the role of $\alpha$-synuclein/lipid interactions in the pathogenesis of PD (Polymeropoulos et al., 1997; Kruger et al., 1998; Zarranz et al., 2004; Appel-Cresswell et al., 2013; Lesage et al., 2013; Proukakis et al., 2013).

$\alpha$-Synuclein is mainly distributed in the presynaptic nerve terminals in the cerebral cortex, hippocampus and striatum. It mostly presents in the synaptic vesicle fraction (Lee et al., 2008). Coincidentally, the early pathological change detected during the progression of $\mathrm{PD}$ is the presynaptic degeneration of dopaminergic neurons in the striatum, long before the death of the cell bodies (Fahn, 2003; Sossi et al., 2004; Kurowska et al., 2016). It is now generally accepted that $\alpha$-synuclein binds to synaptic vesicles. The evidence on its role in sensing and stabilizing the curvature of these tiny organelles is much more recent and still emerging. Regarding the function of $\alpha$-synuclein in vesicle endocytosis, different views are emerging (Lautenschlager et al., 2017).

In the sucrose density gradient centrifugation experiment, wild-type $\alpha$-synuclein, its mutant A30P $\alpha$-synuclein, and the vesicle marker molecule synaptophysin were all present in the low-density component of synaptic proteins. $\alpha$-Synuclein is believed to be a soluble protein located at the presynaptic end and is involved in the regulation of synaptic activity, plasticity, and transport of synaptic vesicle pools (Rizzoli and Betz, 2005; Lautenschlager et al., 2017, 2018). The pre-synaptic distribution of $\alpha$-synuclein appears after synapse formation, indicating that $\alpha$-synuclein has no decisive effect on the formation of synapses. However, when the normal expression of $\alpha$-synuclein is suppressed, the number of vesicles in the vesicle recycling pool and vesicle reserve pool farther from the active region in the presynaptic tip is reduced (Rizzoli and Betz, 2005), but the number of easily released vesicles which are near or anchored in the active area is not affected (Murphy et al., 2000). In the electrophysiology experiments, undertaking long-term stimulation, the release of vesicles from $\alpha$-synuclein knockout mice is less than that of wild-type mouse, indicating that in the absence of $\alpha$-synuclein in the presynaptic terminals of neurons, the number of vesicles in the vesicle circulation region is not maintained and replenished in a timely manner (Barbiroli et al., 2002). But acute injection of human wild-type monomeric $\alpha$-synuclein into lamprey synaptic terminals strongly stimulates the neurons, which can significantly reduce the rate of endocytosis, leading to CCVs accumulation (Busch et al., 2014) and synaptic fidelity in the calyx of held (Eguchi et al., 2017). Taken together, this indicates that maintenance of normal $\alpha$-synuclein expression levels is necessary to ensure an appropriate number of synaptic vesicles, in the presynaptic terminals.

Except for the monomeric $\alpha$-synuclein mentioned above, different $\alpha$-synuclein conformations or strains may also exert distinct effects on SVE. For example, $\alpha$-synuclein dimers lead to the formation of unique clathrin-coated pits (Medeiros et al., 2017). Multimers of $\alpha$-synuclein may affect the early stages of CCVs formation and fission, while monomeric $\alpha$-synuclein may affect the final step of clathrin-uncoating (Wang et al., 2014). Further studies found that $\alpha$-synuclein is an important regulator of presynaptic terminal size and organizer of different synapses vesicle pools by specifically regulating between the synaptic vesicles and the plasma membrane (Vargas et al., 2017). In recent years, studies on the relationship between $\alpha$-synuclein and proteins in the SNARE complex indicate that it plays a role in regulating the release of synaptic vesicles (Choi et al., 2013). The interaction of $\alpha$-synuclein and SNARE protein complex regulates the release of neurotransmitters from presynaptic vesicles (Darios et al., 2010; Burre et al., 2014). These studies together suggest that $\alpha$-synuclein plays 
an important role in regulating the recycling of synaptic vesicles by endocytosis.

\section{LRRK2 in SVE}

In 2002, scientists identified a mutation in LRRK2 (PARK8), an important pathogenic gene on chromosome 18 in a family of Japanese patients with hereditary PD (Funayama et al., 2002). Two years later, two groups reported that two LRRK2 mutations also existed in two unrelated families of PD patients in Europe (Paisan-Ruiz et al., 2004; Zimprich et al., 2004). Up to now, several mutations of LRRK2, such as R1396G, R1441C, Y1654C, Y1699C, 11122V, I2020T, and G2019S have been reported to increase the incidence of PD. Transgenic mice expressing the R1441C mutant LRRK2 can partially replicate the phenotype of PD, such as decreased dopamine levels and abnormalities in the nigrostriatal projection (Li Y. et al., 2009). The phenotypic study of LRRK2 G2019S mutant transgenic mice suggests that although there is no significant loss of dopaminergic neurons in the substantia nigra, the dopamine content and dopamine release in the striatum and intake levels were decreased significantly (Li et al., 2010). Overexpression of mutation LRRK2 G2019S in mouse brain induced PD-like pathology (Xiong et al., 2017). Introducing G2019S mutant LRRK2 in stem cells derived from patients with $\mathrm{PD}$ can lead to degenerative phenotype. These results indicate that mutant $L R R K 2$ can directly cause PD-related changes (Liu et al., 2012).

Although the cause of PD induced by mutations in the LRRK2 gene is not clear, there is some evidence to support the hypothesis that LRRK2 protein, like $\alpha$-synuclein, can affect the dopamine system by regulating the recycling of presynaptic vesicles. LRRK2 protein exists in synaptic components rich in vesicles and membrane structures in the rat brain, and is distributed by dots in synapses (Biskup et al., 2006). It can be speculated that it may be related to the cell membrane and synaptic vesicle structure. Chemical inhibition of LRRK2 has been shown to delay endocytosis, indicating normal serine/threonine kinase activity of LRRK2 is essential for proper SVE (Arranz et al., 2015). In addition, LRRK2 mutant mouse showed an accumulation of CCVs and reduced synaptic vesicle density in dopaminergic neuronal terminals (Xiong et al., 2018).

Due to the lack of a distinct transmembrane region, LRRK2 may loosely bind to synaptic vesicles by interacting with membrane and presynaptic proteins. Recent studies have identified some proteins that are specifically involved in SVE regulation, and are interacting partners and/or substrates of LRRK2, such as dynamin, Rab5b (one of Rab proteins), endophillin A1, and synaptojanin 1. The major function of dynamin is mediating CCVs to fusion from the plasma membrane. LRRK2 has been reported to interact with dynamin, and regulate its GTPase activity (Stafa et al., 2014). LRRK2 achieves its effect on synaptic vesicle circulation by interacting with vesicle endocytosis-related proteins Rab5b and endophillin A1 (Shin et al., 2008). Moreover, LRRK2 can phosphorylate endophillin A1 at positions T73 and S75 in its BAR domain, and LRRK2-mediated phosphorylation of S75 endophillin A1 plays a key role in mediating the function of endophillin A1 in synapses (Matta et al., 2012; Ambroso et al., 2014). Recent synaptic proteomic analysis of the LRRK2 mutant Drosophila model has also identified synaptojanin 1 , which is essential for synaptic vesicle recycling, as a substrate of LRRK2 kinase (Islam et al., 2016). LRRK2 phosphorylates synaptojanin 1 at positions T1131 and T1205 located in its PPR domain, resulting in defective synaptojanin 1-endophilin A1 interaction (Islam et al., 2016; Pan et al., 2017). To sum up, LRRK2 kinase activity can regulate many steps of SVE, and the pathogenic mutation of LRRK2 may aggravate the deficient of SVE, leading to downstream toxic effects and thus degeneration of dopaminergic neurons.

\section{Parkin in SVE}

Parkin mutation was found in patients with autosomal recessive PD (Kitada et al., 1998). Parkin, encoded by PRKN (also known as PARK2), is a component protein in the ubiquitin ligase complex. Its mutation causes the malfunction of ubiquitin ligase, which causes the deposit of its substrate (such as $\alpha$-synuclein, etc.) in neurons (Shimura et al., 2001). Parkin is widely distributed in the brain. Unlike $\alpha$-synuclein and LRRK2, it is evenly distributed in the cytoplasm of neurons without enriching the presynaptic terminals (Shimura et al., 1999). PRNK knockout mouse shows abnormalities in neurotransmission (Periquet et al., 2005). As an E3 ubiquitin ligase, Parkin has been shown to ubiquitinate endophilin A1, whose major binding partners are dynamin and synaptojanin 1 (Cao et al., 2014). It has been reported that the ubiquitination of Parkin is responsible for regulating the expression level of endophilin A1. It can also regulate protein's ability to recruit and bind its interaction partners at the plasma membrane and CCV interface (Trempe et al., 2009; Cao et al., 2014). These data suggest that Parkin E3 ubiquitin ligase function may be an important regulator of synaptic vesicle recycling, and PRKN mutations that cause loss of E3 ligase function may negatively affect the process of SVE.

\section{PINK1 in SVE}

The mutations of PINK1 (PARK6) and DJ-1 (PARK7) genes cause recessive familial PD (Valente et al., 2004). It is believed that these mutations cause fewer cases of recessive familial hereditary PD than Parkin mutations. The molecular mechanisms underlying PINK1 and DJ-1 mutation remain unclear. However, both of them are closely related to synaptic vesicle activity. In Drosophila neurons, PINK1 dysfunction does not change the basic level of synaptic vesicle release, but vesicles in the vesicle pool cannot be efficiently transported to the active zone to be released when the synapse is rapidly and strongly stimulated, causing the synaptic release to become weaker compared to wild type after long-term stimulation (Morais et al., 2009). PINK1 mutants exhibited reduced levels of other proteins involved in synaptic transmission, and the synaptic vesicles with PINK1 mutants had broken membranes (Doktor et al., 2018). The lack of PINK1 leads to increased hippocampal excitatory transmission and release of neurotransmitters, which may lead to cognitive impairments in PD (Feligioni et al., 2016). PINK1 mutants have disrupted synaptic mitophagy, which is crucial in maintaining the health 
of the pre-synaptic terminal (Vidyadhara et al., 2019). PINK1 and parkin have also been reported to associate with lipid rafts, implying that functional alteration of lipid rafts by these proteins may regulate lipid rafts-dependent endocytosis (Silvestri et al., 2005; Cha et al., 2015).

\section{DJ-1 in SVE}

DJ-1 has been reported to be closely linked to the plasma membrane and interact with synaptophysin and Rab3A, the synaptic vesicle proteins (Usami et al., 2011). DJ-1 deficiency impairs synaptic vesicle endocytosis and re-availability in synapses, without structural alterations (Kyung et al., 2018). DJ1 mutants (M26I, E64D, and L166P) were unable to rescue the endocytosis defects of synaptic vesicles, while the expression of wild-type DJ-1 completely restored the endocytic function of DJ$1 \mathrm{KO}$ neurons (Kyung et al., 2018). These results indicate that DJ1 is essential for synaptic vesicle endocytosis and reavailability, and impairment of this function by PD-associated DJ-1 mutants may be related to the pathogenesis of PD.

In shorts, more and more evidence has been found to suggest that PD-related genes including SNCA, LRRK2, PRKN, PINK1, and $D J-1$ are involved in synaptic vesicle exocytosis, endocytosis, and recycling. The role of $\alpha$-synuclein in the process of vesicle activity has been most extensively studied. There are many reports on the role of LRRK2 in the process of SVE, but the underlying mechanisms remain unclear. The study of Parkin, PINK1 and DJ-1 genes is relatively rare.

\section{Mutations of SVE Genes in PD}

Recently, several SVE-related genes have been discovered to be involved in PD, further supporting the importance of SVE defects in the pathogenesis of PD.

\section{Mutations of DNAJC6 in PD}

DNAJC6 encodes auxilin, which is an enzyme of putative tyrosine-protein phosphatase. Auxilin is a cofactor for hsc70 and its $J$ domain is responsible for recruitment of the ATPase to stimulate clathrin-coat removal (Saheki and De Camilli, 2012; Nguyen and Krainc, 2018). Mutations in DNAJC6 were initially described in atypical Parkinsonism patients (Edvardson et al., 2012). Homozygous mapping of two patients with juvenile PD showed that a harmful splice site mutation in DNAJC6, c.801-2 A > G, resulted in a significant decrease in mRNA levels (Edvardson et al., 2012). Another study found that one patient had a DNAJC6 homozygous truncated mutation Q734X, which caused almost $20 \%$ loss of the C-terminus, including its functional J domain that is responsible for binding to HSC70 (Koroglu et al., 2013). Recent studies have reported other DNAJC6 mutations, such as R927G and T741T, are associated with early onset PD cases (Olgiati et al., 2016). These diseaserelated mutations link DNAJC6 to the pathogenesis of PD. These mutations result in reduced auxin expression and are expected to reduce their overall function (Olgiati et al., 2016).

\section{Mutations of SYNJ1 in PD}

Synaptojanin 1 is an inositol phosphatase enriched at the presynaptic terminals. Synaptojanin 1 is a $145-\mathrm{kDa}$ protein that contains three functional domains: a SAC1-like domain that hydrolyzes inositol monophosphates such as PI3P and PI4P; a 5'-phosphatase domain that hydrolyzes PI $(4,5) \mathrm{P}_{2}$ to produce PI4P; and a highly variable $\mathrm{C}$-terminal prolinerich domain that can be recruited by endophilin A1 during SVE. All three domains are involved in regulating the SVE at various stages of synaptic activity (Mani et al., 2007). The Sac1 domain homologous to yeast SacIp mainly dephosphorylates phosphatidylinositol monophosphate present in organelle membranes (including the membranes of the Golgi apparatus and endosomes) to recruit proteins required for membrane transport. The 5-phosphatase domain hydrolyzes the phosphate group at the D-5 position of phosphatidylinositol diphosphate or triphosphate located on the plasma membrane to activate endocytosis or cytoskeletal reorganization, and other pathways (Mcintire et al., 2014). SYNJ1 is necessary for normal SVE and membrane passage, and controls the number and release time of vesicles in the synapses of sensory neurons (Drouet and Lesage, 2014). Cytoplasmic SYNJ1 protein was directed to endocytic sites thanks to protein-protein interactions through its C-terminal PRD domain with Src homology 3 (SH3) domain-containing proteins. The C-terminal region to SYNJ1 was shown to interact with the SH3 domains of a variety of proteins implicated in synaptic vesicle recycling and trafficking, subcellular targeting, and signaling such as endophilin, amphiphysins, or intersectin. These domains play their role in SVE by interacting with their phosphohydrolases and endocytosisrelated proteins.

The association of R258Q and R459P mutations in SYNJ1 with juvenile or early onset PD was recently reported in several independent studies (Krebs et al., 2013; Quadri et al., 2013). A homozygous R258Q mutation of SYNJ1 caused early onset PD in an Italian family. Knock-in mice carrying the homozygous R258Q disease allele, which abolishes the SAC1 activity required for hydrolyzing PI3P and PI4P, recapitulated parkinsonian symptoms and exhibited defective clathrin uncoating of SVs and dystrophic changes in the nigrostriatal terminals (Krebs et al., 2013; Cao et al., 2017). The mutation of R459P is the same as that of R258, and the mutation sites are all in the Sac-like domain. If these sites are mutated, they will affect the function of the Sac1 domain, and the function of SYNJ1 will also be problematic. Synj1 heterozygous deletion $\left(\right.$ Synj $\left.1^{ \pm}\right)$, which is associated with an impaired 5' -phosphatase activity, also leads to Parkinson's disease (PD)-like pathologies in mice (Pan et al., 2020). A homozygous mutation of R459P in SYNJ1 had been identified in an Indian family with autosomal recessive juvenile Parkinsonism (Olgiati et al., 2014; Kirola et al., 2016). These mutations are located in the Sac1 domain of synaptojanin 1 and impair its mulitphosphatase activity (Krebs et al., 2013; Quadri et al., 2013; Olgiati et al., 2014). Interestingly, the insufficient haploid function of synaptojanin 1 caused delayed SVE of dopaminergic neurons in the midbrain of mice, but not cortical neurons, suggesting that the loss of synaptojanin 1 function may specifically affect vulnerable 
dopaminergic neurons in the pathogenesis of PD. Moreover, through genetic engineering techniques, these mutant mouse models have PD phenotypes, such as age-dependent motor function abnormalities as well as $\alpha$-synuclein accumulation, impaired autophagy and dopaminergic terminal degeneration (Cao et al., 2017; Pan et al., 2020). These results show that SYNJ1 plays an important role in SVE, and its variants play a more critical role in the pathogenesis of PD. Further research is needed on the role of SYNJ1 in the development of PD.

\section{Synaptic Gene SH3GL2 Mutation in PD}

Recently, a large-scale GWAS meta-analysis reported that SH3GL2 (encode endophilin A1) was identified as a PD risk factor (Chang et al., 2017). Endophilin A1 is involved in SVE regulation. Moreover, research in 2018 confirmed that not only the variant of SH3GL2, but also changes in the binding domain of its microRNA can cause the onset of PD (Ghanbari et al., 2016). In addition, earlier studies have confirmed that SH3GL2 plays a key role in the normal function of CNS. Its dysfunction is involved in the occurrence and development of PD disease (Shi et al., 2009). However, even though the physiological function of endorphin A1 in neural terminals is well understood, its specific molecular mechanism in the pathogenesis of $\mathrm{PD}$ remains unclear.

\section{ANIMAL MODELS BASED ON SVE GENES DEMONSTRATE DISTINCT PD PHENOTYPES}

Mouse models knockout of DNAJC6, SYNJ1, and SH3GL2 all showed endocytosis defects at the synapses, highlighting the importance of proper SVE control in maintaining axonal terminal integrity (Kim et al., 2002; Yim et al., 2010; Milosevic et al., 2011). Previous reports have shown that presynaptic compartments in auxilin knockout mice display SVE-deficient features, including reduced synaptic vesicle density, increased CCVs, and membraneless clathrin cages (Yim et al., 2010). However, subsequent studies found that genetic ablation of the auxilin homolog of GAK(Cyclin-G-associated kinase) and DNAJC6 can lead to lethality in embryonic mice, while overexpression of the C-terminal fragment and J domain of GAK binding to clathrin can rescue the phenotype of the mice (Beilina et al., 2014; Nalls et al., 2014; Park et al., 2015). In cell models, clathrin was additionally coat to vesicle by GAK and auxilin. Therefore, these evidences suggest that auxilin induced dysfunction in PD could be potentially rescued by overexpression of GAK. In addition, the lack of auxilin in Drosophila causes age-related motor dysfunction and accelerates $\alpha$-synuclein-mediated dopaminergic neuron loss (Song et al., 2017). These results indicate that the dopaminergic neurons are more sensitive to the loss of auxilin function. Consistent with previous reports, synapses in SYNJ1 R258Q knock-in mice show severe endocytosis defects and more CCVs and other endocytosis intermediates (Cao et al., 2017). Moreover, dystrophic neural terminals were observed in the dorsal striatum of these mice, which is the main site of substantia nigra compact dopaminergic neuron projection in the brain. In addition, auxilin and parkin levels are reported to be elevated in SYNJ1 mutant mice (Cao et al., 2017). Synj1 heterozygous deletion $\left(\operatorname{Synj1} 1^{ \pm}\right)$, which is associated with an impaired $5^{\prime}$-phosphatase activity, also leads to Parkinson's disease (PD)-like pathologies in mice (Pan et al., 2020). Endophilin A triple knockout (TKO) mice were fatal shortly after birth. Mice with endophilin A deficiency exhibit age-dependent dyskinesia and progressive ataxia, reminiscent of neurodegeneration in endophilin A1 and endophilin A2 double deletion (DKO) mice phenotype (Tanasic et al., 2011; Murdoch et al., 2016). Mouse models of the endophilin A1 gene knockout also show elevated levels of parkin and CCV accumulation, highlighting the potential functional connection between these SVE proteins and parkin (Kjaerulff et al., 2011). These transgenic animal models once again demonstrate that SVE-related genes are involved in the onset and development of PD.

\section{OTHER PATHWAYS INVOLVED IN REGULATION BY SVE}

We summarized PD-related genes involved in the regulation of SVE, and SVE-related gene mutations are involved in the pathogenesis of PD. It is believed that SVE is essential to maintain the homeostasis and health of the presynaptic membrane. If SVE dysfunction, it may lead to axon degeneration, leading to the onset of PD. In fact, in the pathogenesis of $\mathrm{PD}$, the accumulation and spread of misfolded proteins, and Lewy Body formation, are the major mechanisms (MahulMellier et al., 2020). The function of SVE is also related to the accumulation and spread of misfolded proteins, such as $\alpha$-synuclein. Among them, SYNJ1, the above-mentioned important endocytic protein, its heterozygotes may promote the aggregation and high phosphorylation of $\alpha$-synuclein (Pan et al., 2020). The dysfunction of SVE may be to only the dysfunction of endolysosomal system, which leads to the spread of the misfolded protein (Vidyadhara et al., 2019). Furthermore, SVE is an important physiological mechanism involved in the balance and transformation of lipids, phosphatidylinositol in synapses, axons, and even the soma. SVE also involves organelles and other physiological functions, such as autophagy and mitophagy. If SVE is dysfunctional, autophagy and mitophagy would also have abnormal performance, which will inevitably affect the normal functions of synapses and axons (Pan et al., 2020). Besides the regulation of SVE at the synapse, several endocytic genes have also been identified as critical modulators of synaptic autophagy, a pathway for the maintenance of synaptic protein homeostasis and turnover via the lysosome following neurotransmission (Soukup et al., 2018). Likewise, mitochondria, an important organelle, may be due to the decrease of ATP and the increase of reactive oxygen species due to SVE dysfunction, which further leads to the onset of PD (Nguyen et al., 2019). In the study of lipids, studies have shown that the possibility of 
lipid rafts is also involved in the aggregation and positioning of $\alpha$-synuclein (Brummel et al., 2017). Dysregulation of lipid rafts-dependent endocytosis may caused cell-to-cell transmission of $\alpha$-synuclein was facilitated (Cha et al., 2015). SVE-related proteins, such as SYNJ1, are involved in the metabolic balance of phosphatidylinositol, whether it will affect lipid rafts, whether they will participate in the aggregation of asyn and the spread of pathological asyn, which are worthy of further research and discussion. Based on these evidences and speculations, we summarized the pathways and physiopathological functions that SVE may be involved in the pathogenesis of PD (see Figure 2).

\section{CONCLUSION AND PERSPECTIVES}

The pathogenesis of $\mathrm{PD}$ remains unclear, which presents a major obstacle to the development of neuroprotective therapies. SVE dysfunction is involved in presynaptic nerve terminal degeneration. Emerging evidence suggests that the dysfunction of SVE is tightly related to the onset of PD. Several PDrelated genes were found to play a role in regulating SVE and synaptic function, while at the same time, mutations in key genes of SVE play a role in the pathogenesis of PD (see Figure 1 and Table 1). SVE dysfunction involves the degeneration of presynaptic nerve terminals, autophagy and mitophagy disorder,

TABLE 1 | Summary of PD-linked and SVE-associated genes information in this article.

\begin{tabular}{|c|c|c|c|c|c|}
\hline Gene & Location & Protein & Function & Mutation & $\begin{array}{l}\text { Animal model involved in } \\
\text { the pathogenesis of PD }\end{array}$ \\
\hline SNCA & $\begin{array}{l}\text { (Human) } \\
\text { Chromosome 4, } \\
\text { 4q22.1 (Mouse) } \\
\text { Chromosome 6, } 6 \\
\text { B3| } 629.15 \mathrm{cM}\end{array}$ & $\alpha$-Synuclein & $\begin{array}{l}\text { The major protein component of the Lewy } \\
\text { body in the brain of patients with PD. }\end{array}$ & $\begin{array}{l}\text { A30P, E46K, H50Q, G51D, and } \\
\text { A53T }\end{array}$ & $\begin{array}{c}\text { Mice expressing mutant } \\
\alpha \text {-synuclein, or overexpression } \\
\text { of wild-type } \alpha \text {-synuclein, SNCA } \\
\text { knockout model, acute injection } \\
\text { of virus encoding wild-type or } \\
\text { mutant } \alpha \text {-synuclein, or } \\
\alpha \text {-synuclein pre-formed fibrils }\end{array}$ \\
\hline LRRK2 & $\begin{array}{l}\text { (Human) } \\
\text { Chromosome 12, } \\
\text { 12q12 (Mouse) } \\
\text { Chromosome 15, }\end{array}$ & $\begin{array}{l}\text { Leucine-rich repeat } \\
\text { kinase } 2\end{array}$ & $\begin{array}{l}\text { LRRK2 is a kinase that is located largely in } \\
\text { the cytoplasm but also associates with the } \\
\text { mitochondrial outer membrane. LRRK2 } \\
\text { interacts with the C-terminal R2 ring finger }\end{array}$ & $\begin{array}{l}\text { R1396G, R1441C, Y1654C, } \\
\text { Y1699C, I1122V, I2020T, and } \\
\text { G2019S. }\end{array}$ & $\begin{array}{l}\text { Mice with G2019S R1441C } \\
\text { mutant. Chemical inhibition of } \\
\text { LRRK2. LRRK2 knockout mice }\end{array}$ \\
\hline
\end{tabular}

PRKN 15| 15 E3

(Human) Parkin

Chromosome 6,

6q26 (Mouse)

Chromosome 17,

17A1| $177.8 \mathrm{cM}$

PIKN1

(Human)

Chromosome 1,

1p36.12 (Mouse)

Chromosome 4, 4|

4 D3

$\begin{array}{lll}\text { DJ-1 } & \text { (Human) } & \text { human protein } \\ & \text { Chromosome 1, deglycase DJ-1 } \\ & \text { 1p36.23 (Mouse) } \\ & \text { Chromosome 4, 4| } \\ & 4 \text { E2 } \\ \text { DNAJC6 } & \text { (Human) Auxilin } \\ & \text { Chromosome 1, } \\ & \text { 1p31.3 (Mouse) } \\ & \text { Chromosome 4, 4| } \\ & 4 \text { C6 } \\ & \text { (Human) } \\ \text { SYNJ1 } & \text { Chromosome 21, } \\ & \text { 21q22.2 (Mouse) } \\ & \text { Chromosome 16, } \\ & \text { 16| 16 52.18 cM } \\ & \text { (Human) } \\ & \text { Chromosome 9, } \\ & \text { 9p22.2 (Mouse) } \\ & \text { Chromosome 4, 4 } \\ \text { C4l } 4 \text { 40.23 cM }\end{array}$

\section{domain of Parkin}

Parkin is a 465-residue E3 ubiquitin ligase R256C, R275W, G328E, A398T, that plays a critical role in ubiquitination- the and $\mathrm{T} 415 \mathrm{~N}$; heterozygous mutation process whereby molecules are covalently labeled with ubiquitin and directed toward degradation in proteasomes or lysosomes.

PTEN-induced kinase 1PINK1 is a mitochondrial

serine/threonine-protein kinase, which is thought to protect cells from stress-induced mitochondrial dysfunction. PINK1 activity causes the parkin protein to bind to depolarized mitochondria to induce autophagy of those mitochondria. PINK1 is processed by healthy mitochondria and released to trigger neuron differentiation

DJ-1 protects neurons against oxidative stress and cell death. DJ-1 acts as a positive regulator of androgen receptor-dependent transcription.

Auxilin regulates molecular chaperone activity by stimulating ATPase activity. Auxilin is a putative tyrosine-protein phosphatase.

R246X, H271Q, E417G, L347P, and Q239X/R492X heterozygous PINK1 mutations

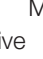
Me 126I, E64D, and L166P
Q734X, R927G, and T741T
Synaptojanin 1 is a protein involved
in vesicle uncoating in neurons. This is an
important regulatory lipid phosphatase.

Endophilin A1 is a member of the BAR protein family involved in membrane deformation, and its $\mathrm{SH} 3$ domain in the carboxyl-terminal is capable of recruiting dynamin and synaptojanin 1
R258Q and R459P Homozygous R258Q mutation

F10E, A66D, and A63S/A66S/M70Q (or called "SSQ") heterozygous mutation
Parkin knockout mice

PINK1 knockout mice, PINK1-deficient mouse and lack of PINK1 in Drosophila

DJ-1 knockout mice

DNAJC6 knockout mouse Auxilin knockout Drosophila
SYNJ1 knockout SYNJ1 heterozygote and triploid

EndoA triple knockout (TKO) mice Endophilin knockout mice heterozygous mutation of endophilin in Drosophila 


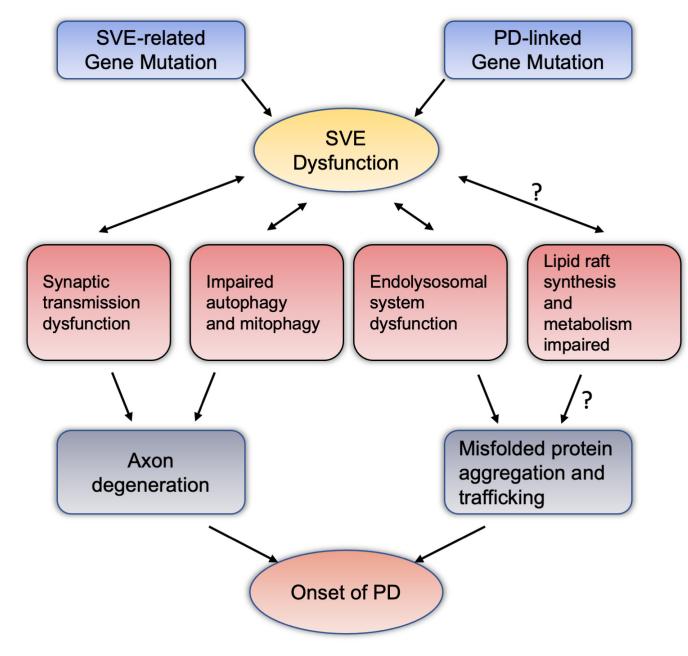

FIGURE 2 | Synaptic vesicle endocytosis dysfunction potentially mediate dopaminergic neurodegeneration through intersections with various pathway. Mutations in the PD-related genes or SVE-related genes reviewed in this article may cause damage to the endocytosis of vesicles at the terminal axons of neurons. SVE may interact with synaptic transmission, autophagy and mitochondrial autophagy, and the endolysosomal system has the effect of this two-way condition. These pathways can lead to the accumulation and spread of misfolded proteins with axon degeneration or neurotoxicity, and ultimately lead to the pathogenesis of PD. Among them, regarding the relationship between SVE and lipid raft synthesis and metabolism, the mechanism of abnormal lipid raft metabolism leading to the pathogenesis of PD deserves more research and attention. PD, Parkinson's disease; SVE, synaptic vesicle endocytosis.

and through a variety of ways and means, participates in the abnormal aggregation and transport of neurotoxic misfolded proteins. Participating in the above changes, these mechanisms can indicate that SVE dysfunction may be involved in the pathogenesis of PD (see Figure 2). Although existing evidence suggests that SVE is regulated by a set of overlapping genes, how these are converted to regulate different pathways remains to be elucidated. More studies are needed to illustrate the role of SVE in regulating synaptic function and PD pathology. It should be noted that the mammalian CNS neurotransmission systems are highly complex in time and space, making the illustration of its role in PD more difficult. Further research is needed to address these important issues. An in-depth understanding of the interaction between SVE and multiple signaling pathways or key mechanisms may be the most appropriate target for early diagnosis and provide possible new targets for therapeutic intervention of PD.

\section{GLOSSARY}

Amphipathic helix: $\alpha$-helical protein structure segregating hydrophobic and polar residues.

Adaptor protein: Here specifically refers to clathrin adaptor protein, also known as adaptation protein, which is a vesicle transport adaptor protein related to clathrin.
BAR domains: In molecular biology, BAR domains are highly conserved protein dimerization domains that occur in many proteins involved in membrane dynamics in a cell. The BAR domain is banana-shaped and binds to membrane via its concave face. It is capable of sensing membrane curvature by binding preferentially to curved membranes.

Bulk endocytosis: membrane uptake by large membrane invagination.

Clathrin-mediated endocytosis: one of endocytosis, which is characterized by a coating of vesicles with the clathrintriskelion scaffold.

E3 ubiquitin ligase: A ubiquitin ligase is a protein that recruits an E2 ubiquitin-conjugating enzyme that has been loaded with ubiquitin, recognizes a protein substrate, and assists or directly catalyzes the transfer of ubiquitin from the E2 to the protein substrate.

Endocytosis: uptake of molecules from the extracellular space into the cell by forming cell invaginations. In the case of endocytosis at the synaptic terminal, the endocytosis is deemed to retrieve excess membrane rather than molecules.

Endosomal-lysosomal system: The endosomal-lysosomal system is made up of a set of intracellular membranous compartments that dynamically interconvert, which is comprised of early endosomes, recycling endosomes, late endosomes, and the lysosome.

GAK: Cyclin-G-associated kinase, the ubiquitously expressed J-domain protein, is essential for the chaperoning and uncoating of clathrin that is mediated by Hsc70.

Kiss-and-run: mechanism of exocytosis, where the synaptic vesicle opens only a small fusion pore. This pore reseals easily afterward and so the vesicle is kept intact. This in contrast to the full fusion event, where the synaptic vesicle collapses and both, vesicle and presynaptic membrane fuse together.

LRRK2: leucine-rich repeat kinase 2; enzymatic protein encoded by the PARK8 gene.

Rab proteins: proteins that present manifold involvement in membrane trafficking, including vesicle formation, transport and fusion.

\section{AUTHOR CONTRIBUTIONS}

LZ contributed to article writing and graphic design while YT helped with figure construction and tabulation, and ZZ provided fund support and manuscript proof. All authors read and approved the final manuscript.

\section{FUNDING}

This work was supported by grants from the National Natural Science Foundation of China (Nos.81822016, 81771382, and 81571249) to ZZ. 


\section{REFERENCES}

Ambroso, M. R., Hegde, B. G., and Langen, R. (2014). Endophilin A1 induces different membrane shapes using a conformational switch that is regulated by phosphorylation. Proc. Natl. Acad. Sci. U S A. 111, 6982-6987. doi: 10.1073/ pnas. 1402233111

Appel-Cresswell, S., Vilarino-Guell, C., Encarnacion, M., Sherman, H., Yu, I., Shah, B., et al. (2013). Alpha-synuclein p.H50Q, a novel pathogenic mutation for Parkinson's disease. Mov. Disord. 28, 811-813. doi: 10.1002/mds. 25421

Arranz, A. M., Delbroek, L., Van Kolen, K., Guimaraes, M. R., Mandemakers, W., Daneels, G., et al. (2015). LRRK2 functions in synaptic vesicle endocytosis through a kinase-dependent mechanism. J. Cell Sci. 128, 541-552. doi: 10.1242/ jcs. 158196

Barbiroli, B., Gaiani, S., Lodi, R., Iotti, S., Tonon, C., Clementi, V., et al. (2002). Abnormal brain energy metabolism shown by in vivo phosphorus magnetic resonance spectroscopy in patients with chronic liver disease. Brain Res. Bull. 59, 75-82. doi: 10.1016/s0361-9230(02)00839-0

Beilina, A., Rudenko, I. N., Kaganovich, A., Civiero, L., Chau, H., Kalia, S. K., et al. (2014). Unbiased screen for interactors of leucine-rich repeat kinase 2 supports a common pathway for sporadic and familial Parkinson disease. Proc. Natl. Acad. Sci. U S A. 111, 2626-2631.

Biskup, S., Moore, D. J., Celsi, F., Higashi, S., West, A. B., Andrabi, S. A., et al. (2006). Localization of LRRK2 to membranous and vesicular structures in mammalian brain. Ann. Neurol. 60, 557-569. doi: 10.1002/ana.21019

Brummel, B. E., Braun, A. R., and Sachs, J. N. (2017). Polyunsaturated chains in asymmetric lipids disorder raft mixtures and preferentially associate with alphaSynuclein. Biochim. Biophys. Acta Biomembr. 1859, 529-536. doi: 10.1016/j. bbamem.2016.10.006

Burke, R. E., and O'malley, K. (2013). Axon degeneration in Parkinson's disease. Exp. Neurol. 246, 72-83. doi: 10.1016/j.expneurol.2012.01.011

Burre, J., Sharma, M., and Sudhof, T. C. (2014). alpha-Synuclein assembles into higher-order multimers upon membrane binding to promote SNARE complex formation. Proc. Natl. Acad. Sci. U S A. 111, E4274-E4283.

Busch, D. J., Oliphint, P. A., Walsh, R. B., Banks, S. M., Woods, W. S., George, J. M., et al. (2014). Acute increase of alpha-synuclein inhibits synaptic vesicle recycling evoked during intense stimulation. Mol. Biol. Cell 25, 3926-3941. doi: 10.1091/mbc.e14-02-0708

Cao, M., Milosevic, I., Giovedi, S., and De Camilli, P. (2014). Upregulation of Parkin in endophilin mutant mice. J. Neurosci. 34, 16544-16549. doi: 10.1523/ jneurosci.1710-14.2014

Cao, M., Wu, Y., Ashrafi, G., Mccartney, A. J., Wheeler, H., Bushong, E. A., et al. (2017). Parkinson Sac Domain Mutation in Synaptojanin 1 Impairs Clathrin Uncoating at Synapses and Triggers Dystrophic Changes in Dopaminergic Axons. Neuron 93, 882-896e885.

Cha, S. H., Choi, Y. R., Heo, C. H., Kang, S. J., Joe, E. H., Jou, I., et al. (2015). Loss of parkin promotes lipid rafts-dependent endocytosis through accumulating caveolin-1: implications for Parkinson's disease. Mol. Neurodegener. 10:63.

Chanaday, N. L., Cousin, M. A., Milosevic, I., Watanabe, S., and Morgan, J. R. (2019). The Synaptic Vesicle Cycle Revisited: New Insights into the Modes and Mechanisms. J. Neurosci. 39, 8209-8216. doi: 10.1523/jneurosci.1158-19.2019

Chang, D., Nalls, M. A., Hallgrimsdottir, I. B., Hunkapiller, J., Van Der Brug, M., Cai, F., et al. (2017). A meta-analysis of genome-wide association studies identifies 17 new Parkinson's disease risk loci. Nat. Genet. 49, 1511-1516.

Chang-Ileto, B., Frere, S. G., Chan, R. B., Voronov, S. V., Roux, A., and Di Paolo, G. (2011). Synaptojanin 1-mediated PI(4,5)P2 hydrolysis is modulated by membrane curvature and facilitates membrane fission. Dev. Cell 20, 206-218. doi: 10.1016/j.devcel.2010.12.008

Chen, C. K., Bregere, C., Paluch, J., Lu, J. F., Dickman, D. K., and Chang, K. T. (2014). Activity-dependent facilitation of Synaptojanin and synaptic vesicle recycling by the Minibrain kinase. Nat. Commun. 5:4246.

Chen, L., Ding, Y., Cagniard, B., Van Laar, A. D., Mortimer, A., Chi, W., et al. (2008). Unregulated cytosolic dopamine causes neurodegeneration associated with oxidative stress in mice. J. Neurosci. 28, 425-433. doi: 10.1523/jneurosci. 3602-07.2008

Cheng, H. C., Ulane, C. M., and Burke, R. E. (2010). Clinical progression in Parkinson disease and the neurobiology of axons. Ann. Neurol. 67, 715-725. doi: 10.1002/ana.21995
Choi, B. K., Choi, M. G., Kim, J. Y., Yang, Y., Lai, Y., Kweon, D. H., et al. (2013). Large alpha-synuclein oligomers inhibit neuronal SNARE-mediated vesicle docking. Proc. Natl. Acad. Sci. U S A. 110, 4087-4092. doi: 10.1073/pnas. 1218424110

Cottrell, J. R., Li, B., Kyung, J. W., Ashford, C. J., Mann, J. J., Horvath, T. L., et al. (2016). Calcineurin $\mathrm{A} \gamma$ is a functional phosphatase that modulates synaptic vesicle endocytosis. J. Biol. Chem. 291, 1948-1956. doi: 10.1074/jbc.m115. 705319

Cousin, M. A. (2017). Integration of Synaptic Vesicle Cargo Retrieval with Endocytosis at Central Nerve Terminals. Front. Cell Neurosci. 11:234. doi: 10. 3389/fncel.2017.00234

Cousin, M. A., and Robinson, P. J. (2001). The dephosphins: dephosphorylation by calcineurin triggers synaptic vesicle endocytosis. Trends Neurosci. 24, 659-665. doi: 10.1016/s0166-2236(00)01930-5

Darios, F., Ruiperez, V., Lopez, I., Villanueva, J., Gutierrez, L. M., and Davletov, B. (2010). Alpha-synuclein sequesters arachidonic acid to modulate SNAREmediated exocytosis. EMBO Rep. 11, 528-533. doi: 10.1038/embor.2010.66

Dauer, W., and Przedborski, S. (2003). Parkinson's disease: mechanisms and models. Neuron 39, 889-909.

Daumke, O., Roux, A., and Haucke, V. (2014). BAR domain scaffolds in dynaminmediated membrane fission. Cell 156, 882-892. doi: 10.1016/j.cell.2014.02.017

Davidson, W. S., Jonas, A., Clayton, D. F., and George, J. M. (1998). Stabilization of alpha-synuclein secondary structure upon binding to synthetic membranes. J. Biol. Chem. 273, 9443-9449. doi: 10.1074/jbc.273.16.9443

De Lau, L. M., and Breteler, M. M. (2006). Epidemiology of Parkinson's disease. Lancet Neurol. 5, 525-535.

Doktor, B., Damulewicz, M., Krzeptowski, W., Bednarczyk, B., and Pyza, E. M. (2018). Effects of PINK1 mutation on synapses and behavior in the brain of Drosophila melanogaster. Acta Neurobiol. Exp. 78, 231-241. doi: 10.21307/ane2018-021

Drouet, V., and Lesage, S. (2014). Synaptojanin 1 mutation in Parkinson's disease brings further insight into the neuropathological mechanisms. BioMed Res. Int. 2014:289728.

Edvardson, S., Cinnamon, Y., Ta-Shma, A., Shaag, A., Yim, Y. I., Zenvirt, S., et al. (2012). A deleterious mutation in DNAJC6 encoding the neuronalspecific clathrin-uncoating co-chaperone auxilin, is associated with juvenile parkinsonism. PLoS One 7:e36458. doi: 10.1371/journal.pone.0036458

Eguchi, K., Taoufiq, Z., Thorn-Seshold, O., Trauner, D., Hasegawa, M., and Takahashi, T. (2017). Wild-Type Monomeric alpha-Synuclein Can Impair Vesicle Endocytosis and Synaptic Fidelity via Tubulin Polymerization at the Calyx of Held. J. Neurosci. 37, 6043-6052. doi: 10.1523/jneurosci.0179-17.2017

Eiden, L. E., Schafer, M. K., Weihe, E., and Schutz, B. (2004). The vesicular amine transporter family (SLC18): amine/proton antiporters required for vesicular accumulation and regulated exocytotic secretion of monoamines and acetylcholine. Pflugers Arch. 447, 636-640. doi: 10.1007/s00424-003-1100-5

Eisenberg, E., and Greene, L. E. (2007). Multiple roles of auxilin and hsc70 in clathrin-mediated endocytosis. Traffic 8, 640-646. doi: 10.1111/j.1600-0854. 2007.00568.x

Fahn, S. (2003). Description of Parkinson's disease as a clinical syndrome. Ann. N Y. Acad. Sci. 991, 1-14. doi: 10.1016/b978-0-12-374028-1.00001-4

Farsi, Z., Gowrisankaran, S., Krunic, M., Rammner, B., Woehler, A., Lafer, E. M., et al. (2018). Clathrin coat controls synaptic vesicle acidification by blocking vacuolar ATPase activity. Elife 7:e32569.

Feligioni, M., Mango, D., Piccinin, S., Imbriani, P., Iannuzzi, F., Caruso, A., et al. (2016). Subtle alterations of excitatory transmission are linked to presynaptic changes in the hippocampus of PINK1-deficient mice. Synapse 70, 223-230. doi: 10.1002/syn.21894

Frost, A., Unger, V. M., and De Camilli, P. (2009). The BAR domain superfamily: membrane-molding macromolecules. Cell 137, 191-196. doi: 10.1016/j.cell. 2009.04.010

Funayama, M., Hasegawa, K., Kowa, H., Saito, M., Tsuji, S., and Obata, F. (2002). A new locus for Parkinson's disease (PARK8) maps to chromosome 12p11.2q13.1. Ann. Neurol. 51, 296-301. doi: 10.1002/ana.10113

Galic, M., Jeong, S., Tsai, F. C., Joubert, L. M., Wu, Y. I., Hahn, K. M., et al. (2012). External push and internal pull forces recruit curvature-sensing N-BAR domain proteins to the plasma membrane. Nat. Cell Biol. 14, 874-881. doi: $10.1038 /$ ncb2533 
Ghanbari, M., Darweesh, S. K., De Looper, H. W., Van Luijn, M. M., Hofman, A., Ikram, M. A., et al. (2016). Genetic Variants in MicroRNAs and Their Binding Sites Are Associated with the Risk of Parkinson Disease. Hum. Mutat. 37, 292-300. doi: 10.1002/humu.22943

Giasson, B. I., Murray, I. V., Trojanowski, J. Q., and Lee, V. M. (2001). A hydrophobic stretch of 12 amino acid residues in the middle of alpha-synuclein is essential for filament assembly. J. Biol. Chem. 276, 2380-2386. doi: 10.1074/ jbc.m008919200

He, L., and Wu, L. G. (2007). The debate on the kiss-and-run fusion at synapses. Trends Neurosci. 30, 447-455. doi: 10.1016/j.tins.2007.06.012

Hua, Y., Sinha, R., Thiel, C. S., Schmidt, R., Huve, J., Martens, H., et al. (2011). A readily retrievable pool of synaptic vesicles. Nat. Neurosci. 14, 833-839.

Imig, C., Min, S.-W., Krinner, S., Arancillo, M., Rosenmund, C., Südhof, T. C., et al. (2014). The morphological and molecular nature of synaptic vesicle priming at presynaptic active zones. Neuron 84, 416-431. doi: 10.1016/j.neuron.2014. 10.009

Islam, M. S., Nolte, H., Jacob, W., Ziegler, A. B., Putz, S., Grosjean, Y., et al. (2016). Human R1441C LRRK2 regulates the synaptic vesicle proteome and phosphoproteome in a Drosophila model of Parkinson's disease. Hum. Mol. Genet. 25, 5365-5382.

Kagi, G., Bhatia, K. P., and Tolosa, E. (2010). The role of DAT-SPECT in movement disorders. J. Neurol. Neurosurg. Psychiat. 81, 5-12. doi: 10.1136/jnnp.2008. 157370

Kelly, B. T., Graham, S. C., Liska, N., Dannhauser, P. N., Honing, S., Ungewickell, E. J., et al. (2014). Clathrin adaptors. AP2 controls clathrin polymerization with a membrane-activated switch. Science 345, 459-463. doi: 10.1126/science. 1254836

Kim, W. T., Chang, S., Daniell, L., Cremona, O., Di Paolo, G., and De Camilli, P. (2002). Delayed reentry of recycling vesicles into the fusion-competent synaptic vesicle pool in synaptojanin 1 knockout mice. Proc. Natl. Acad. Sci. U S A. 99, 17143-17148. doi: 10.1073/pnas.222657399

Kirola, L., Behari, M., Shishir, C., and Thelma, B. K. (2016). Identification of a novel homozygous mutation Arg459Pro in SYNJ1 gene of an Indian family with autosomal recessive juvenile Parkinsonism. Parkinson. Relat. Disord. 31, 124-128. doi: 10.1016/j.parkreldis.2016. 07.014

Kitada, T., Asakawa, S., Hattori, N., Matsumine, H., Yamamura, Y., Minoshima, S., et al. (1998). Mutations in the parkin gene cause autosomal recessive juvenile parkinsonism. Nature 392, 605-608. doi: 10.1038/33416

Kjaerulff, O., Brodin, L., and Jung, A. (2011). The structure and function of endophilin proteins. Cell Biochem. Biophys. 60, 137-154. doi: 10.1007/s12013010-9137-5

Koroglu, C., Baysal, L., Cetinkaya, M., Karasoy, H., and Tolun, A. (2013). DNAJC6 is responsible for juvenile parkinsonism with phenotypic variability. Parkinsonism Relat. Disord. 19, 320-324. doi: 10.1016/j.parkreldis.2012. 11.006

Krebs, C. E., Karkheiran, S., Powell, J. C., Cao, M., Makarov, V., Darvish, H., et al. (2013). The Sacl domain of SYNJ1 identified mutated in a family with early-onset progressive Parkinsonism with generalized seizures. Hum. Mutat. 34, 1200-1207. doi: 10.1002/humu.22372

Kruger, R., Kuhn, W., Muller, T., Woitalla, D., Graeber, M., Kosel, S., et al. (1998). Ala30Pro mutation in the gene encoding alpha-synuclein in Parkinson's disease. Nat. Genet. 18, 106-108.

Kurowska, Z., Kordower, J. H., Stoessl, A. J., Burke, R. E., Brundin, P., Yue, Z., et al. (2016). Is Axonal Degeneration a Key Early Event in Parkinson's Disease? J. Parkinsons Dis. 6, 703-707. doi: 10.3233/jpd-160881

Kyung, J. W., Kim, J. M., Lee, W., Ha, T. Y., Cha, S. H., Chung, K. H., et al. (2018). DJ-1 deficiency impairs synaptic vesicle endocytosis and reavailability at nerve terminals. Proc. Natl. Acad. Sci. U S A. 115, 1629-1634. doi: 10.1073/ pnas. 1708754115

Lautenschlager, J., Kaminski, C. F., and Kaminski Schierle, G. S. (2017). alphaSynuclein - Regulator of Exocytosis, Endocytosis, or Both? Trends Cell Biol. 27, 468-479. doi: 10.1016/j.tcb.2017.02.002

Lautenschlager, J., Stephens, A. D., Fusco, G., Strohl, F., Curry, N., Zacharopoulou, M., et al. (2018). C-terminal calcium binding of alpha-synuclein modulates synaptic vesicle interaction. Nat. Commun. 9:712.

Lee, C. S., Samii, A., Sossi, V., Ruth, T. J., Schulzer, M., Holden, J. E., et al. (2000). In vivo positron emission tomographic evidence for compensatory changes in presynaptic dopaminergic nerve terminals in Parkinson's disease. Ann. Neurol. 47, 493-503. doi: 10.1002/1531-8249(200004)47:4<493::aid-ana13>3.0.co;2-4

Lee, H.-J., Suk, J.-E., Bae, E.-J., Lee, J.-H., Paik, S. R., and Lee, S.-J. (2008). Assembly-dependent endocytosis and clearance of extracellular a-synuclein. Int. J. Biochem. Cell Biol. 40, 1835-1849. doi: 10.1016/j.biocel.2008.01.017

Lesage, S., Anheim, M., Letournel, F., Bousset, L., Honore, A., Rozas, N., et al. (2013). G51D alpha-synuclein mutation causes a novel parkinsonian-pyramidal syndrome. Ann. Neurol. 73, 459-471. doi: 10.1002/ana.23894

Li, L. H., Qin, H. Z., Wang, J. L., Wang, J., Wang, X. L., and Gao, G. D. (2009). Axonal degeneration of nigra-striatum dopaminergic neurons induced by 1-methyl-4-phenyl-1,2,3,6-tetrahydropyridine in mice. J. Int. Med. Res. 37, 455-463. doi: 10.1177/147323000903700221

Li, X., Patel, J. C., Wang, J., Avshalumov, M. V., Nicholson, C., Buxbaum, J. D., et al. (2010). Enhanced striatal dopamine transmission and motor performance with LRRK2 overexpression in mice is eliminated by familial Parkinson's disease mutation G2019S. J. Neurosci. 30, 1788-1797. doi: 10.1523/jneurosci.5604-09. 2010

Li, Y., Liu, W., Oo, T. F., Wang, L., Tang, Y., Jackson-Lewis, V., et al. (2009). Mutant LRRK2(R1441G) BAC transgenic mice recapitulate cardinal features of Parkinson's disease. Nat. Neurosci. 12, 826-828. doi: 10.1038/nn.2349

Liu, G. H., Qu, J., Suzuki, K., Nivet, E., Li, M., Montserrat, N., et al. (2012). Progressive degeneration of human neural stem cells caused by pathogenic LRRK2. Nature 491, 603-607. doi: 10.1038/nature11557

Mahul-Mellier, A.-L., Burtscher, J., Maharjan, N., Weerens, L., Croisier, M., Kuttler, F., et al. (2020). The process of Lewy body formation, rather than simply $\alpha$ synuclein fibrillization, is one of the major drivers of neurodegeneration. Proc. Natl. Acad. Sci. U S A. 117, 4971-4982. doi: 10.1073/pnas.1913904117

Mani, M., Lee, S. Y., Lucast, L., Cremona, O., Di Paolo, G., De Camilli, P., et al. (2007). The dual phosphatase activity of synaptojanin1 is required for both efficient synaptic vesicle endocytosis and reavailability at nerve terminals. Neuron 56, 1004-1018. doi: 10.1016/j.neuron.2007.10.032

Marks, B., Stowell, M. H., Vallis, Y., Mills, I. G., Gibson, A., Hopkins, C. R., et al. (2001). GTPase activity of dynamin and resulting conformation change are essential for endocytosis. Nature 410, 231-235. doi: 10.1038/35065645

Matta, S., Van Kolen, K., Da Cunha, R., Van Den Bogaart, G., Mandemakers, W., Miskiewicz, K., et al. (2012). LRRK2 controls an EndoA phosphorylation cycle in synaptic endocytosis. Neuron 75, 1008-1021. doi: 10.1016/j.neuron.2012. 08.022

Mcintire, L. B., Lee, K. I., Chang-Ileto, B., Di Paolo, G., and Kim, T. W. (2014). Screening assay for small-molecule inhibitors of synaptojanin 1, a synaptic phosphoinositide phosphatase. J. Biomol. Screen 19, 585-594. doi: 10.1177/ 1087057113510177

Mcmahon, H. T., and Boucrot, E. (2011). Molecular mechanism and physiological functions of clathrin-mediated endocytosis. Nat. Rev. Mol. Cell Biol. 12, $517-$ 533. doi: 10.1038/nrm3151

Medeiros, A. T., Soll, L. G., Tessari, I., Bubacco, L., and Morgan, J. R. (2017). alphaSynuclein Dimers Impair Vesicle Fission during Clathrin-Mediated Synaptic Vesicle Recycling. Front. Cell Neurosci. 11:388. doi: 10.3389/fncel.2017.00388

Milosevic, I. (2018). Revisiting the Role of Clathrin-Mediated Endoytosis in Synaptic Vesicle Recycling. Front. Cell Neurosci. 12:27. doi: 10.3389/fncel.2018. 00027

Milosevic, I., Giovedi, S., Lou, X., Raimondi, A., Collesi, C., Shen, H., et al. (2011) Recruitment of endophilin to clathrin-coated pit necks is required for efficient vesicle uncoating after fission. Neuron 72, 587-601. doi: 10.1016/j.neuron.2011. 08.029

Morais, V. A., Verstreken, P., Roethig, A., Smet, J., Snellinx, A., Vanbrabant, M., et al. (2009). Parkinson's disease mutations in PINK1 result in decreased Complex I activity and deficient synaptic function. EMBO Mol. Med. 1, 99-111. doi: 10.1002/emmm.200900006

Morgan, J. R., Augustine, G. J., and Lafer, E. M. (2002). Synaptic vesicle endocytosis: the races, places, and molecular faces. Neuromol. Med. 2, 101-114. doi: 10.1385/ nmm:2:2:101

Morgan, J. R., Prasad, K., Jin, S., Augustine, G. J., and Lafer, E. M. (2001). Uncoating of clathrin-coated vesicles in presynaptic terminals: roles for Hsc70 and auxilin. Neuron 32, 289-300. doi: 10.1016/s0896-6273(01)00467-6

Murdoch, J. D., Rostosky, C. M., Gowrisankaran, S., Arora, A. S., Soukup, S. F., Vidal, R., et al. (2016). Endophilin-A Deficiency Induces the Foxo3aFbxo32 Network in the Brain and Causes Dysregulation of Autophagy and the 
Ubiquitin-Proteasome System. Cell Rep. 17, 1071-1086. doi: 10.1016/j.celrep. 2016.09.058

Murphy, D. D., Rueter, S. M., Trojanowski, J. Q., and Lee, V. M. Y. (2000). Synucleins Are Developmentally Expressed, and $\alpha$-Synuclein Regulates the Size of the Presynaptic Vesicular Pool in Primary Hippocampal Neurons. J. Neurosci. 20, 3214-3220. doi: 10.1523/jneurosci.20-09-03214.2000

Nalls, M. A., Pankratz, N., Lill, C. M., Do, C. B., Hernandez, D. G., Saad, M., et al. (2014). Large-scale meta-analysis of genome-wide association data identifies six new risk loci for Parkinson's disease. Nat. Genet. 46, 989-993.

Nguyen, M., and Krainc, D. (2018). LRRK2 phosphorylation of auxilin mediates synaptic defects in dopaminergic neurons from patients with Parkinson's disease. Proc. Natl. Acad. Sci. U S A. 115, 5576-5581. doi: 10.1073/pnas. 1717590115

Nguyen, M., Wong, Y. C., Ysselstein, D., Severino, A., and Krainc, D. (2019). Synaptic, Mitochondrial, and Lysosomal Dysfunction in Parkinson's Disease. Trends Neurosci. 42, 140-149. doi: 10.1016/j.tins.2018.11.001

Olgiati, S., De Rosa, A., Quadri, M., Criscuolo, C., Breedveld, G. J., Picillo, M., et al. (2014). PARK20 caused by SYNJ1 homozygous Arg258Gln mutation in a new Italian family. Neurogenetics 15, 183-188. doi: 10.1007/s10048-014-0406-0

Olgiati, S., Quadri, M., Fang, M., Rood, J. P., Saute, J. A., Chien, H. F., et al. (2016). DNAJC6 Mutations Associated With Early-Onset Parkinson's Disease. Ann Neurol. 79, 244-256.

Paisan-Ruiz, C., Jain, S., Evans, E. W., Gilks, W. P., Simon, J., Van Der Brug, M., et al. (2004). Cloning of the gene containing mutations that cause PARK8-linked Parkinson's disease. Neuron 44, 595-600. doi: 10.1016/j.neuron.2004.10.023

Pan, P. Y., Li, X., Wang, J., Powell, J., Wang, Q., Zhang, Y., et al. (2017). Parkinson's Disease-Associated LRRK2 Hyperactive Kinase Mutant Disrupts Synaptic Vesicle Trafficking in Ventral Midbrain Neurons. J. Neurosci. 37, 11366-11376. doi: 10.1523/jneurosci.0964-17.2017

Pan, P. Y., Sheehan, P., Wang, Q., Zhu, X., Zhang, Y., Choi, I., et al. (2020). Synj1 haploinsufficiency causes dopamine neuron vulnerability and alpha-synuclein accumulation in mice. Hum. Mol. Genet. 29, 2300-2312. doi: 10.1093/hmg/ ddaa080

Park, B. C., Yim, Y. I., Zhao, X., Olszewski, M. B., Eisenberg, E., and Greene, L. E. (2015). The clathrin-binding and J-domains of GAK support the uncoating and chaperoning of clathrin by Hsc70 in the brain. J. Cell Sci. 128, 3811-3821. doi: $10.1242 /$ jcs. 171058

Pechstein, A., Gerth, F., Milosevic, I., Japel, M., Eichhorn-Grunig, M., Vorontsova, O., et al. (2015). Vesicle uncoating regulated by $\mathrm{SH} 3-\mathrm{SH} 3$ domain-mediated complex formation between endophilin and intersectin at synapses. EMBO Rep. 16, 232-239. doi: 10.15252/embr.201439260

Peelaerts, W., Bousset, L., Van Der Perren, A., Moskalyuk, A., Pulizzi, R., Giugliano, M., et al. (2015). alpha-Synuclein strains cause distinct synucleinopathies after local and systemic administration. Nature 522, 340-344. doi: 10.1038/ nature 14547

Pelkmans, L., Fava, E., Grabner, H., Hannus, M., Habermann, B., Krausz, E., et al. (2005). Genome-wide analysis of human kinases in clathrin- and caveolae/raftmediated endocytosis. Nature 436, 78-86. doi: 10.1038/nature03571

Periquet, M., Corti, O., Jacquier, S., and Brice, A. (2005). Proteomic analysis of parkin knockout mice: alterations in energy metabolism, protein handling and synaptic function. J. Neurochem. 95, 1259-1276. doi: 10.1111/j.1471-4159.2005. 03442.x

Polymeropoulos, M. H., Lavedan, C., Leroy, E., Ide, S. E., Dehejia, A., Dutra, A., et al. (1997). Mutation in the alpha-synuclein gene identified in families with Parkinson's disease. Science 276, 2045-2047. doi: 10.1126/science.276.5321.2045

Proukakis, C., Dudzik, C. G., Brier, T., Mackay, D. S., Cooper, J. M., Millhauser, G. L., et al. (2013). A novel alpha-synuclein missense mutation in Parkinson disease. Neurology 80, 1062-1064. doi: 10.1212/wnl.0b013e31828727ba

Qing, H., Wong, W., Mcgeer, E. G., and Mcgeer, P. L. (2009). Lrrk2 phosphorylates alpha synuclein at serine 129: Parkinson disease implications. Biochem. Biophys. Res. Commun. 387, 149-152. doi: 10.1016/j.bbrc.2009.06.142

Quadri, M., Fang, M., Picillo, M., Olgiati, S., Breedveld, G. J., Graafland, J., et al. (2013). Mutation in the SYNJ1 gene associated with autosomal recessive, earlyonset Parkinsonism. Hum. Mutat. 34, 1208-1215. doi: 10.1002/humu.22373

Ramanan, V., Agrawal, N. J., Liu, J., Engles, S., Toy, R., and Radhakrishnan, R. (2011). Systems biology and physical biology of clathrin-mediated endocytosis. Integr. Biol. 3, 803-815. doi: 10.1039/c1ib00036e
Rizzoli, S. O., and Betz, W. J. (2005). Synaptic vesicle pools. Nat. Rev. Neurosci. 6 , 57-69.

Rohrbough, J., and Broadie, K. (2005). Lipid regulation of the synaptic vesicle cycle. Nat. Rev. Neurosci. 6, 139-150. doi: 10.1038/nrn1608

Saheki, Y., and De Camilli, P. (2012). Synaptic vesicle endocytosis. Cold Spring Harb. Perspect. Biol. 4:a005645.

Schirinzi, T., Madeo, G., Martella, G., Maltese, M., Picconi, B., Calabresi, P., et al. (2016). Early synaptic dysfunction in Parkinson's disease: Insights from animal models. Mov. Disord. 31, 802-813. doi: 10.1002/mds.26620

Schulz-Schaeffer, W. J. (2010). The synaptic pathology of alpha-synuclein aggregation in dementia with Lewy bodies, Parkinson's disease and Parkinson's disease dementia. Acta Neuropathol. 120, 131-143. doi: 10.1007/s00401-0100711-0

Schuske, K. R., Richmond, J. E., Matthies, D. S., Davis, W. S., Runz, S., Rube, D. A., et al. (2003). Endophilin is required for synaptic vesicle endocytosis by localizing synaptojanin. Neuron 40, 749-762. doi: 10.1016/s0896-6273(03) 00667-6

Serra, P. A., Sciola, L., Delogu, M. R., Spano, A., Monaco, G., Miele, E., et al. (2002). The neurotoxin 1-methyl-4-phenyl-1,2,3,6-tetrahydropyridine induces apoptosis in mouse nigrostriatal glia. Relevance to nigral neuronal death and striatal neurochemical changes. J. Biol. Chem. 277, 34451-34461. doi: 10.1074/ jbc.m202099200

Shi, M., Bradner, J., Bammler, T. K., Eaton, D. L., Zhang, J., Ye, Z., et al. (2009). Identification of glutathione S-transferase pi as a protein involved in Parkinson disease progression. Am. J. Pathol. 175, 54-65. doi: 10.2353/ajpath.2009.081019

Shimura, H., Hattori, N., Kubo, S., Yoshikawa, M., Kitada, T., Matsumine, H., et al. (1999). Immunohistochemical and subcellular localization of Parkin protein: absence of protein in autosomal recessive juvenile parkinsonism patients. Ann Neurol. 45, 668-672. doi: 10.1002/1531-8249(199905)45:5<668::aid-ana19>3.0. co; $2-\mathrm{z}$

Shimura, H., Schlossmacher, M. G., Hattori, N., Frosch, M. P., Trockenbacher, A., Schneider, R., et al. (2001). Ubiquitination of a new form of alpha-synuclein by parkin from human brain: implications for Parkinson's disease. Science 293, 263-269. doi: 10.1126/science.1060627

Shin, N., Jeong, H., Kwon, J., Heo, H. Y., Kwon, J. J., Yun, H. J., et al. (2008). LRRK2 regulates synaptic vesicle endocytosis. Exp. Cell Res. 314, 2055-2065. doi: 10.1016/j.yexcr.2008.02.015

Silvestri, L., Caputo, V., Bellacchio, E., Atorino, L., Dallapiccola, B., Valente, E. M., et al. (2005). Mitochondrial import and enzymatic activity of PINK1 mutants associated to recessive parkinsonism. Hum. Mol. Genet. 14, 3477-3492. doi: $10.1093 / \mathrm{hmg} / \mathrm{ddi} 377$

Song, L., He, Y., Ou, J., Zhao, Y., Li, R., Cheng, J., et al. (2017). Auxilin Underlies Progressive Locomotor Deficits and Dopaminergic Neuron Loss in a Drosophila Model of Parkinson's Disease. Cell Rep. 18, 1132-1143. doi: 10. 1016/j.celrep.2017.01.005

Sossi, V., De La Fuente-Fernandez, R., Holden, J. E., Schulzer, M., Ruth, T. J., and Stoessl, J. (2004). Changes of dopamine turnover in the progression of Parkinson's disease as measured by positron emission tomography: their relation to disease-compensatory mechanisms. J. Cereb. Blood Flow Metab. 24, 869-876. doi: 10.1097/01.wcb.0000126563.85360.75

Soukup, S. F., Vanhauwaert, R., and Verstreken, P. (2018). Parkinson's disease: convergence on synaptic homeostasis. EMBO J. 37:e98960.

Soykan, T., Kaempf, N., Sakaba, T., Vollweiter, D., Goerdeler, F., Puchkov, D., et al. (2017). Synaptic Vesicle Endocytosis Occurs on Multiple Timescales and Is Mediated by Formin-Dependent Actin Assembly. Neuron 93, 854. doi: 10.1016/ j.neuron.2017.02.011

Soykan, T., Maritzen, T., and Haucke, V. (2016). Modes and mechanisms of synaptic vesicle recycling. Curr. Opin. Neurobiol. 39, 17-23. doi: 10.1016/j.conb. 2016.03.005

Stafa, K., Tsika, E., Moser, R., Musso, A., Glauser, L., Jones, A., et al. (2014). Functional interaction of Parkinson's disease-associated LRRK2 with members of the dynamin GTPase superfamily. Hum. Mol. Genet. 23, 2055-2077. doi: $10.1093 / \mathrm{hmg} / \mathrm{ddt} 600$

Südhof, T. C. (2004). The synaptic vesicle cycle. Annu. Rev. Neurosci. 27, 509-547.

Tan, T. C., Valova, V. A., Malladi, C. S., Graham, M. E., Berven, L. A., Jupp, O. J., et al. (2003). Cdk5 is essential for synaptic vesicle endocytosis. Nat. Cell Biol. 5, 701-710. doi: 10.1038/ncb1020 
Tanasic, I., Lj, T.-S., Milic Lemic, A., Mitrovic, N., and Milosevic, M. (2011). Enhanced in-vivo bone formation by bone marrow differentiated mesenchymal stem cells grown in chitosan scaffold. J. Bioengineer. Biomed. Sci. 1:2.

Trempe, J. F., Chen, C. X., Grenier, K., Camacho, E. M., Kozlov, G., Mcpherson, P. S., et al. (2009). SH3 domains from a subset of BAR proteins define a Ublbinding domain and implicate parkin in synaptic ubiquitination. Mol. Cell 36, 1034-1047. doi: 10.1016/j.molcel.2009.11.021

Usami, Y., Hatano, T., Imai, S., Kubo, S., Sato, S., Saiki, S., et al. (2011). DJ-1 associates with synaptic membranes. Neurobiol. Dis. 43, 651-662. doi: 10.1016/ j.nbd.2011.05.014

Valente, E. M., Abou-Sleiman, P. M., Caputo, V., Muqit, M. M., Harvey, K., Gispert, S., et al. (2004). Hereditary early-onset Parkinson's disease caused by mutations in PINK1. Science 304, 1158-1160. doi: 10.1126/science.1096284

Vargas, K. J., Schrod, N., Davis, T., Fernandez-Busnadiego, R., Taguchi, Y. V., Laugks, U., et al. (2017). Synucleins Have Multiple Effects on Presynaptic Architecture. Cell Rep. 18, 161-173. doi: 10.1016/j.celrep.2016.12.023

Verstreken, P., Koh, T. W., Schulze, K. L., Zhai, R. G., Hiesinger, P. R., Zhou, Y., et al. (2003). Synaptojanin is recruited by Endophilin to promote synaptic vesicle uncoating. Neuron 40, 733-748. doi: 10.1016/s0896-6273(03)00644-5

Vidyadhara, D. J., Lee, J. E., and Chandra, S. S. (2019). Role of the endolysosomal system in Parkinson's disease. J. Neurochem. 150, 487-506. doi: 10.1111/jnc. 14820

Wang, L., Das, U., Scott, D. A., Tang, Y., Mclean, P. J., and Roy, S. (2014). alphasynuclein multimers cluster synaptic vesicles and attenuate recycling. Curr. Biol. 24, 2319-2326. doi: 10.1016/j.cub.2014.08.027

Watanabe, S., and Boucrot, E. (2017). Fast and ultrafast endocytosis. Curr. Opin. Cell Biol. 47, 64-71. doi: 10.1016/j.ceb.2017.02.013

Watanabe, S., Mamer, L. E., Raychaudhuri, S., Luvsanjav, D., Eisen, J., Trimbuch, T., et al. (2018). Synaptojanin and Endophilin Mediate Neck Formation during Ultrafast Endocytosis. Neuron 98, 1184-1197e1186.

Watanabe, S., Trimbuch, T., Camacho-Perez, M., Rost, B. R., Brokowski, B., Sohl-Kielczynski, B., et al. (2014). Clathrin regenerates synaptic vesicles from endosomes. Nature 515, 228-233. doi: 10.1038/nature13846

Wu, X. S., Zhang, Z., Zhao, W. D., Wang, D. S., Luo, F. J., and Wu, L. G. (2014). Calcineurin Is Universally Involved in Vesicle Endocytosis at Neuronal and
Nonneuronal Secretory Cells. Cell Rep. 7, 982-988. doi: 10.1016/j.celrep.2014. 04.020

Wu, Y., O’toole, E. T., Girard, M., Ritter, B., Messa, M., Liu, X., et al. (2014). A dynamin 1-, dynamin 3- and clathrin-independent pathway of synaptic vesicle recycling mediated by bulk endocytosis. Elife 3:e01621.

Xiong, Y., Neifert, S., Karuppagounder, S. S., Liu, Q., Stankowski, J. N., Lee, B. D., et al. (2018). Robust kinase- and age-dependent dopaminergic and norepinephrine neurodegeneration in LRRK2 G2019S transgenic mice. Proc. Natl. Acad. Sci. U S A. 115, 1635-1640. doi: 10.1073/pnas.1712648115

Xiong, Y., Neifert, S., Karuppagounder, S. S., Stankowski, J. N., Lee, B. D., Grima, J. C., et al. (2017). Overexpression of Parkinson's Disease-Associated Mutation LRRK2 G2019S in Mouse Forebrain Induces Behavioral Deficits and alphaSynuclein Pathology. eNeuro 4, ENEURO.0004-ENEURO.0017.

Yim, Y. I., Sun, T., Wu, L. G., Raimondi, A., De Camilli, P., Eisenberg, E., et al. (2010). Endocytosis and clathrin-uncoating defects at synapses of auxilin knockout mice. Proc. Natl. Acad. Sci. U S A. 107, 4412-4417. doi: 10.1073/pnas. 1000738107

Zarranz, J. J., Alegre, J., Gomez-Esteban, J. C., Lezcano, E., Ros, R., Ampuero, I., et al. (2004). The new mutation, E46K, of alpha-synuclein causes Parkinson and Lewy body dementia. Ann. Neurol. 55, 164-173. doi: 10.1002/ana.10795

Zimprich, A., Biskup, S., Leitner, P., Lichtner, P., Farrer, M., Lincoln, S., et al. (2004). Mutations in LRRK2 cause autosomal-dominant parkinsonism with pleomorphic pathology. Neuron 44, 601-607. doi: 10.1016/j.neuron.2004. 11.005

Conflict of Interest: The authors declare that the research was conducted in the absence of any commercial or financial relationships that could be construed as a potential conflict of interest.

Copyright (c) 2021 Zou, Tian and Zhang. This is an open-access article distributed under the terms of the Creative Commons Attribution License (CC BY). The use, distribution or reproduction in other forums is permitted, provided the original author(s) and the copyright owner(s) are credited and that the original publication in this journal is cited, in accordance with accepted academic practice. No use, distribution or reproduction is permitted which does not comply with these terms. 